\title{
Evaluation of a Novel Anti-Mucin 1 (MUC1) Antibody (PankoMab) as a Potential Diagnostic Tool in Human Ductal Breast Cancer; Comparison with Two Established Antibodies
}

\author{
Darius Dian $^{\mathrm{a}}$ Wolfgang Janni ${ }^{\mathrm{a}} \quad$ Christina Kuhn $^{\mathrm{a}}$ Doris Mayr ${ }^{\mathrm{b}} \quad$ Uwe Karsten $^{\mathrm{c}}$ \\ loannis Mylonas ${ }^{a} \quad K^{a}$ laus Friese ${ }^{a} \quad U^{\prime}$ do Jeschke \\ ${ }^{a}$ Department of Obstetrics and Gynecology, \\ ${ }^{b}$ Department of Pathology, LMU Munich, \\ ${ }^{c}$ Glycotope $\mathrm{GmbH}$, Berlin-Buch, Germany
}

Key Words

Breast cancer · Ca15-3 - Mucin expression .

PankoMab · Prognostic parameters · VU-4-H5

\section{Summary}

Aim: PankoMab is a novel antibody that recognizes a tumor-specific epitope of Mucin 1 (MUC1). The aim of this study was the evaluation of PankoMab as a potential diagnostic tool and its comparison with two established antibodies against MUC1 in human ductal breast cancer. Materials and Methods: Breast carcinomas were obtained from 82 patients. MUC1 expression and hormone receptor status were determined by immunohistochemistry of paraffin-embedded material. Results: PankoMab revealed strong correlation to hormone receptor expression. DF3 showed no correlation with grading, lymph node involvement and/or estrogen receptor (ER) expression. In the subgroup of lymph node-positive and ER-negative tumors, we saw a significantly reduced DF3 staining in G3 tumors compared to G2 tumors. VU-4-H5 showed increased staining intensity in correlation with increased grading. In addition, we also identified a significantly higher expression of the VU-4-H5 epitope in lymph node-positive carcinomas compared to carcinomas without lymph node involvement. Conclusion: PankoMab revealed strong correlation to hormone receptor expression in ductal carcinoma of the breast. VU-4-H5 showed increased staining intensity in correlation with increased grading and lymph node involvement. PankoMab and VU-4-H5 staining could be a useful combination in ductal breast cancer prognosis by immunohistochemistry.

\author{
Schlüsselwörter \\ Mammakarzinom · Ca15-3 · Muzinexpression . \\ PankoMab · Prognosefaktoren · VU-4-H5
}

\section{Zusammenfassung}

Hintergrund: PankoMab ist ein neuer Antikörper, der ein tumorspezifisches Epitop von Mucin 1 (MUC1) erkennt. Ziel der Arbeit war es, PankoMab als diagnostischen Antikörper beim Mammakarzinom zu evaluieren und mit zwei etablierten Antikörpern gegen MUC1 zu vergleichen. Material und Methoden: Mammakarzinomgewebe von 82 Patientinnen wurde entsprechend den aktuellen internationalen Standards klassifiziert. MUC1-Expression und Hormonrezeptorstatus wurden immunhistochemisch an Paraffinblöcken bestimmt. Ergebnisse: PankoMab zeigte eine strenge Korrelation mit der Hormonrezeptorexpression. DF3 zeigte keine Korrelation mit Grading, Nodalstatus und/oder Hormonrezeptorstatus. In der Subgruppe nodalpositiver und hormonrezeptornegativer Tumoren sahen wir eine signifikante Abnahme der DF3-Färbungsintensität von G3-Tumoren verglichen mit G2-Tumoren. VU4-H5 zeigte steigende Färbungsintensität beim höheren Grading. Zusätzlich konnten wir eine höhere Expression von VU-4-H5-Epitopen in nodalpositiven im Vergleich zu nodalnegativen Karzinomen feststellen. Schlussfolgerungen: PankoMab wurde zur Erkennung von MUC1 in Tumoren entwickelt. In dieser Studie zeigte PankoMab eine hohe Korrelation mit der Hormonrezeptorexpression beim duktalen Mammakarzinom. VU-4-5H zeigt steigende Färbungsintensität in Korrelation mit steigendem Grading und Lymphknotenbefall. PankoMab- und VU-4-H5-Färbung könnten eine sinnvolle Kombination zur Prognosebestimmung des Mammakarzinoms sein.

\begin{tabular}{ll}
\hline KARGER & ( 2009 S. Karger GmbH, Freiburg \\
Fax +497614520714 & Accessible online at: \\
Information@Karger.de & www.karger.com/onk \\
www.karger.com &
\end{tabular}




\section{Introduction}

Mucin derives from the word mucus and designates the structural component of it. The O-glycans exhibit high water-binding capacity on the mucins, protect the central protein from proteolysis and are involved in antigen binding and/or signal transduction $[1,2]$. Mucins are divided into two groups: membrane-bound mucins such as Mucin 1 (MUC1) and secreted mucins.

MUC1 (also named CD227, EMA, PAS-O, PEM, MAM6 , or episialin) plays a role in the barrier function of the mucous membranes and helps to regulate cell adhesion. The chromosomal localization was defined as 1q21 [3]. It is a highmolecular-weight transmembrane glycoprotein with unique properties. It is extremely long and its stretched extracellular part consists of identical repeats of a 20 -amino acid peptide, the number of which varies in the population. The repeats are heavily O-glycosylated, with characteristic short glycan chains. This can be monitored directly with monoclonal antibodies (mAbs) to the glycans as well as indirectly with mAbs to peptide epitopes, because their binding is often hindered by the glycans [4].

Cancer cells, especially adenocarcinomas, express aberrant forms and amounts of mucins [5-7]. The expression of distinct exposed oligosaccharide structures confers on tumor cells an enormous range of potential ligands for interaction with other receptors at the cell surface $[8,9]$. An increased and often depolarized expression throughout the entire cell cytoplasm has been recorded [10]. It is generally believed that MUC1 overexpression by tumor cells facilitates invasive growth and metastasis $[11,12]$. It was also thought that overexpression of MUC1 disrupts cell-cell and cell-extracellular matrix adhesions [13-15].

In addition, MUC1 was shown to contribute to cancer cell escape from immune surveillance as MUC1-expressing cells are less susceptible to T cell- and NK cell-mediated lysis [16]. On the other hand, absence of MUC1 expression also occurred and was associated with the absence of estrogen receptors (ERs) and progesterone receptors (PRs) in several breast cancer studies. These findings support the observation by Luna-More et al. [17] that tumors of the human breast negative for MUC1 are high-grade, are ER and PR negative and associated with positive axillary lymph nodes. Other studies also related low or negative MUC1 expression to higher tumor grade and poor prognosis $[18,19]$.
PankoMab is a novel antibody that binds specifically to tumor MUC1. Therefore, the aim of this study was, firstly, to evaluate the new mAb, PankoMab, as a diagnostic tool in ductal invasive breast cancer, secondly, to compare this antibody with the established antibodies DF3 and VU-4-H5 and, thirdly, to correlate all these three antibodies with prognostic parameters (lymph node involvement, grading, and hormone receptor expression).

\section{Patients and Methods}

\section{Patients}

Ductal breast carcinomas were obtained from 82 patients and classified according to current international standards. Tumor, node, metastasis (TNM) classification was done according to the World Health Organization (WHO) system [20]. The histological grading classification was determined according to a modification of the Elston and Ellis grading proposed by Bloom and Richardson [21]. The hormone receptor status was determined by immunohistochemistry on paraffin-embedded material. The immunoreactive score (IRS) was assigned according to Remmele and Stegner [22]. Cells were regarded as hormone receptor positive when there was a positive staining in $\geq 10 \%$ of the tumor cell nuclei (table 1 , see online supplemental material).

\section{Immunohistochemistry}

Immunohistochemistry was performed using a combination of pressure cooker heating and the standard streptavidin-biotin-peroxidase complex with the use of the mouse IgG-Vectastain Elite ABC kit (Vector Laboratories, Burlingame, CA, USA). The mouse mAbs used for these experiments are listed in table 2 .

Paraffin-embedded tissue sections were dewaxed using xylol for 15 min, rehydrated in a descending series of alcohol (100, 96 and 70\%), and subjected to epitope retrieval for $10 \mathrm{~min}$ in a pressure cooker using sodium citrate buffer ( $\mathrm{pH}$ 6.0) containing $0.1 \mathrm{M}$ citric acid and $0.1 \mathrm{M}$ sodium citrate in distilled water. After cooling, sections were washed twice in PBS. Endogenous peroxidase activity was blocked by immersion in $3 \%$ hydrogen peroxide (Merck, Darmstadt, Germany) in methanol for $20 \mathrm{~min}$. Non-specific binding of the primary antibodies was blocked by incubating the sections with diluted normal serum (10 ml PBS containing $150 \mu \mathrm{l}$ horse serum; Vector Laboratories) for $20 \mathrm{~min}$ at room temperature. The sections were then incubated at room temperature for 60 min with the primary antibodies. After washing with PBS, the sections were incubated in diluted biotinylated serum (10 ml PBS containing 50 $\mu \mathrm{l}$ horse serum; Vector Laboratories) for $30 \mathrm{~min}$ at room temperature. After incubation with the avidin-biotin-peroxidase complex (diluted in 10 $\mathrm{ml}$ PBS; Vector Laboratories) for $30 \mathrm{~min}$ and repeated washing steps with PBS, visualization was performed with substrate and the chromogenic compound 3,3'-diaminobenzidine (DAB; Dako, Glostrup, Denmark) for 8-10 min. Sections were counterstained with Mayer's acidic hematoxylin and dehydrated in an ascending series of alcohol (70-100\%). After xylol treatment, the sections were covered. Negative controls were performed by replacing the primary antibody with normal horse serum.
Table 2. Antibodies used in the study

\begin{tabular}{lllll}
\hline Antigen & Clone & Isotype & $\begin{array}{l}\text { Working } \\
\text { concentration }\end{array}$ & Source \\
\hline MUC1 & DF3 (CA15-3) & mouse IgG1 & $1.4 \mu \mathrm{g} / \mathrm{ml}$ & Dako \\
MUC1 & VU-4-H5 & mouse IgG1 & $6.8 \mu \mathrm{g} / \mathrm{ml}$ & Zymed \\
MUC1 & PankoMab & mouse IgG1 & $2.0 \mu \mathrm{g} / \mathrm{ml}$ & Glycotope \\
\hline
\end{tabular}




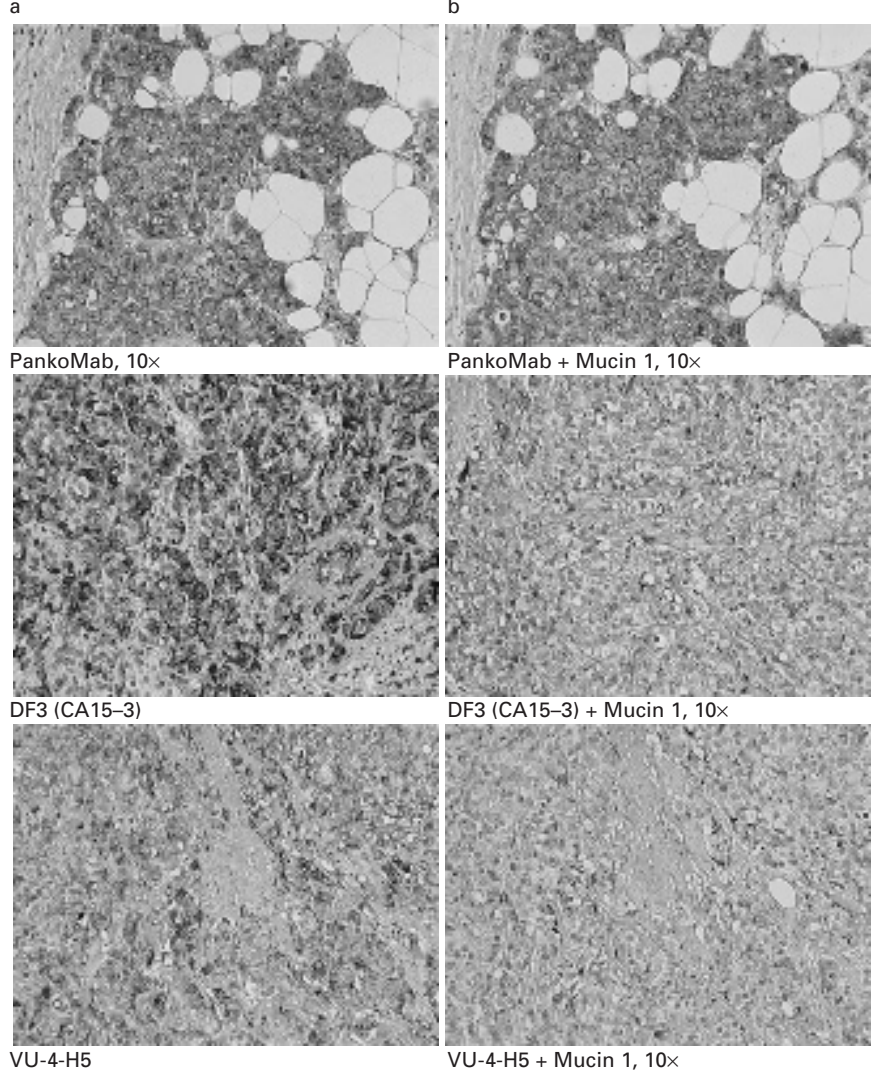

Fig. 1. Specificity control: MUC1 antibodies were incubated with MUC1 positive control reagent and applied to the breast cancer tissue slides. Reduced MUC1 staining in (b) was observed for DF3 and VU-4H5. PankoMab is highly specific for non-shed MUC1. PankoMab staining cannot be reduced with the Tosoh control reagent which represents a soluble and shed form of the MUC1 antigen.

For specificity control, MUC1 antibodies were incubated with $300 \mathrm{U} /$ $\mathrm{ml}$ MUC1-positive control reagent (Tosoh, Tokyo, Japan) and applied to the breast cancer tissue slides. Reduced MUC1 staining in fig. 1b was observed for DF3 (CA15-3) and VU-4-H5. PankoMab is highly specific for non-shed MUC1. PankoMab staining cannot be reduced with the Tosoh control reagent, which represents a soluble and shed form of the MUC1 antigen (fig. 1)

Immunohistochemical staining was performed using an appropriate positive control. Positive cells showed a brownish color, and negative controls, as well as unstained cells, were blue.

The intensity and distribution patterns of specific immunohistochemical staining were evaluated using the semi-quantitative assay as described elsewhere, and used to assess the expression pattern of various marker molecules like steroid receptors, glycodelin and MUC1 [23-25]. The IRS score was calculated by multiplication of the optical staining intensity (graded as $0=$ no, $1=$ weak, $2=$ moderate and $3=$ strong staining) and the percentage of positively stained cells $(0=$ no staining, $1=<10 \%$ of cells, $2=11-50 \%$ of cells, $3=51-80 \%$ of cells and $4=>81 \%$ of cells stained). The slides were examined by two independent observers. Sections were examined using a CCD color camera (JVC, Victor Company of Japan, Japan) and a Leitz (Wetzlar, Germany) microscope.

Statistics

Correlation between MUC1-antibody interaction with common risk factors - grading, lymph node involvement and hormone receptor status
- was analyzed by using a general linear model (GLM). A multivariate logistic regression was used to analyze the correlation between MUC1 and VU-4-H5 simultaneously. The age of the patients was included in the model as covariate. For this purpose, three risk groups were defined, based on tumor grading and hormone receptor status. The low-risk group comprised grading 1 or $2(\mathrm{G} 1 / \mathrm{G} 2)$ and positive receptor status. The highrisk group included grading 3 (G3) and negative receptor status. The intermediate risk was defined by G3 and positive receptor status or G1/G2 with negative receptor status. All analyses were performed by using SAS statistical software V8.2.

\section{Results}

The staining results in the ductal breast carcinomas of all 82 patients are shown in table 1.

\section{PankoMab}

Expression of MUC1 as analyzed with the PankoMab antibody ( $\mathrm{n}=82$, all analyzable) was down-regulated with increased grading. Highest values were measured in G1 and lowest in G3 tumors, although without statistical significance. In addition, there were no differences in MUC1 staining with the PankoMab antibody in invasive ductal carcinomas with or without lymph node metastasis.

However, significant differences in MUC1 staining were found in ER-positive and -negative ductal carcinomas. ERnegative carcinomas showed significantly reduced staining of MUC1 (fig. 2a; $\mathrm{p}=0.0047$ ) compared to ER-positive carcinomas (fig. 2b). A quantitative summary of the staining results is presented in fig. $2 \mathrm{c}$. The results of linear regression using a GLM are shown in table 3.

\section{$D F 3$}

Although the investigation of MUC1 staining with the DF3 antibody ( $\mathrm{n}=81 ; 1$ not analyzable) showed no significant correlation with any of the three prognostic parameters (table 3 ), we were able to detect significant differences in one subgroup. Invasive ductal carcinomas with lymph node metastasis and lack of expression of ER revealed significant differences ( $p=0.046)$ in DF3 staining in G2 compared to G3 tumors. G2 tumors showed very strong expression of MUC1 (fig. 3a) and G3 tumors showed only weak expression of MUC1 (fig. 3b) when analyzed with the antibody DF3. A quantitative summary of this staining result is presented in fig $3 \mathrm{c}$. The results of linear regression are shown in table 3 .

\section{$V U-4-H 5$}

Using the VU-4-H5 antibody ( $\mathrm{n}=79 ; 3$ not analyzable), we could demonstrate a significant correlation with lymph node involvement and grading, but not with the receptor status, by comparing all cases (table 3). In addition, we also found significant differences in one specific subgroup. In ductal carcinomas without lymph node metastasis and no expression of ER, VU-4-H5 staining in G2 tumors was significantly lower 
Table 3. Results of statistical analysis of PankoMab, DF3 and VU-4-H5 staining in ductal breast carcinomas compared to grading, staging and ER expression

\begin{tabular}{lllllrl}
\hline Risk factor & \multicolumn{2}{l}{ PankoMab } & DF3 & \multicolumn{2}{c}{ VU-4-H5 } \\
\cline { 2 - 7 } & Mean square $^{\mathrm{a}}$ & $\mathrm{p}$ Value & Mean square & $\mathrm{p}$ Value & Mean square & $\mathrm{p} \mathrm{Value}$ \\
\hline Lymph node involvement & 13.581 & 0.2822 & 11.281 & 0.4051 & 142.109 & 0.0056 \\
Receptor status & 98.196 & 0.0047 & 19.059 & 0.2799 & 2.456 & 0.7088 \\
Grading & 5.133 & 0.6435 & 21.234 & 0.2733 & 86.244 & 0.0097 \\
\hline
\end{tabular}

${ }^{a}$ Linear regression using a GLM.

Fig. 2. ER-negative carcinomas showed significantly reduced staining with Panko $\operatorname{Mab}(\mathbf{a})(\mathrm{p}=0.0047)$ compared to ERpositive carcinomas (b). A semi-quantitative evaluation of the staining results is presented in a box plot in (c) $(\mathrm{n}=82$ : ER neg. $\mathrm{n}=34$, ER pos. $\mathrm{n}=48)$. The boxes represent the range between the 25 th and 75 th percentiles with a horizontal line at the median. The bars delineate the 5th and 95th percentiles. The IRS score is illustrated on the y-axis.
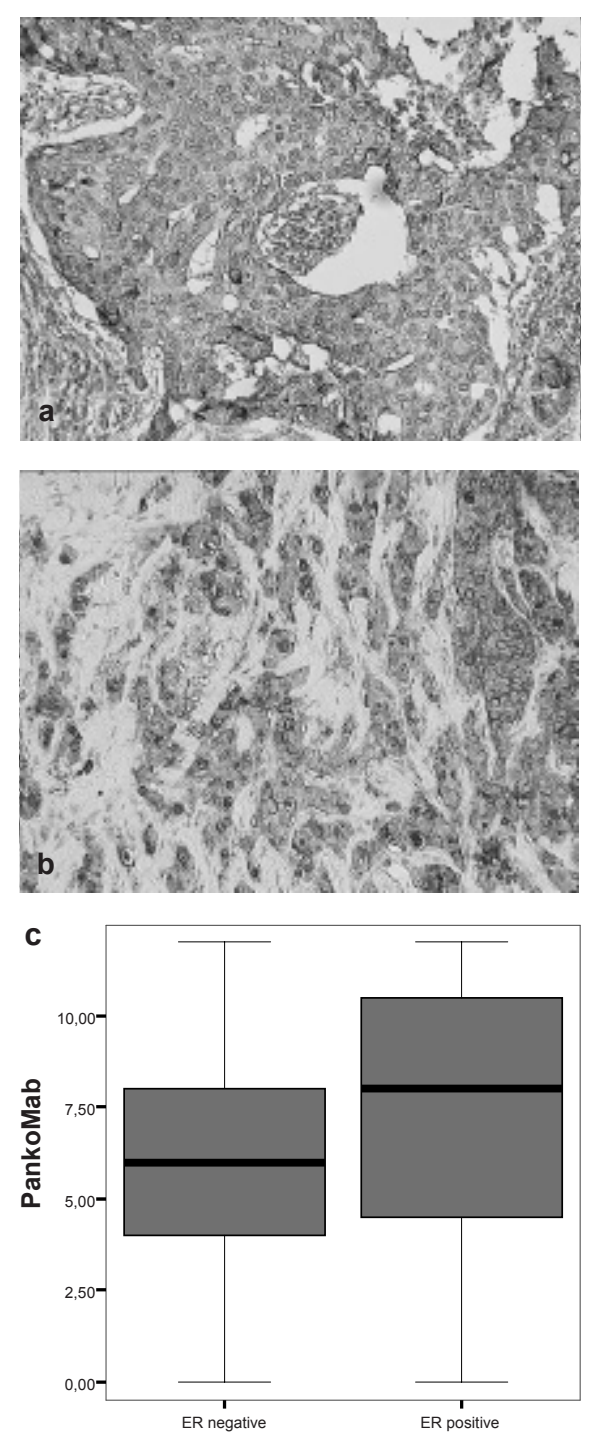

MUC1

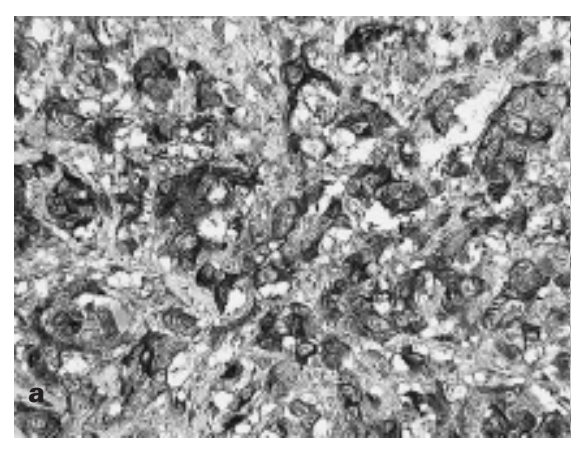

Fig. 3. G2 tumors showed very strong expression of MUC1 (a) and G3 tumors faint expression of MUC1 (b) analyzed with the antibody DF3. A semi-quantitative evaluation of this staining is presented in a box plot in $(\mathbf{c})(\mathrm{n}=20$ : $\mathrm{G} 2 \mathrm{~N}+\mathrm{ER}-\mathrm{n}=10$, $\mathrm{G} 3 \mathrm{~N}+\mathrm{ER}-\mathrm{n}=10$ ). The boxes represent the range between the 25 th and 75 th percentiles with a horizontal line at the median. The bars delineate the 5 th and 95th percentiles. The circles indicate values more than 1.5 box lengths. The IRS score is illustrated on the y-axis.
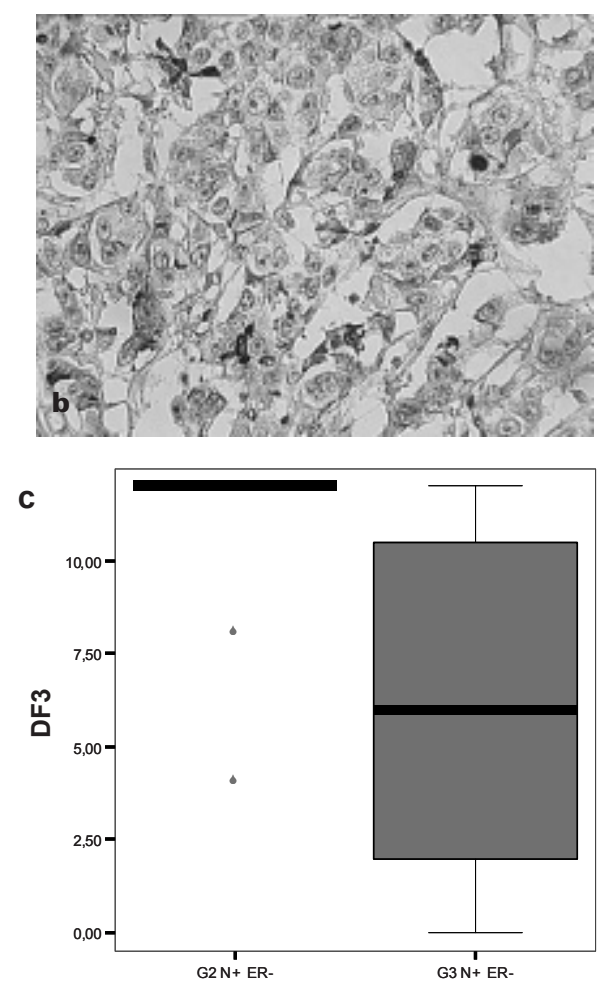

MUC1 (fig. 4a) compared to G3 (fig. $4 \mathrm{~b})$ tumors $(\mathrm{p}=0.008)$. In addition, in ductal carcinomas with lymph node metastasis and expression of ER, increased VU-4-H5 staining from G2 (fig. 4c) to G3 (fig. 4d) tumors was observed, without reaching statistical significance. In contrast to PankoMab and DF3 staining, VU-4-H5 staining was increased from G1 to G3 carcinomas (fig. 4e) and from lymph node-negative to lymph node-positive tumors (fig. 4f). Linear regression results are shown in table 3 .

The results of the multivariate logistic regression analysis to correlate MUC1 and VU-4-H5 simultaneously are shown in table 4. 
Table 4. Results of the multivariate logistic regression analysis to correlate MUC1 and VU-4-H5 simultaneously

\begin{tabular}{llll}
\hline Parameter & \multicolumn{2}{c}{ Coefficient } & p Value \\
\cline { 2 - 3 } & Estimate $^{\mathrm{a}}$ & Standard error & \\
\hline PankoMab & -0.2123 & 0.0696 & 0.0023 \\
VU-4-H5 & 0.0984 & 0.0490 & 0.0448 \\
Age, years & -0.0488 & 0.0222 & 0.0282 \\
\hline
\end{tabular}

${ }^{\mathrm{a} C}$ Cumulative logit model.
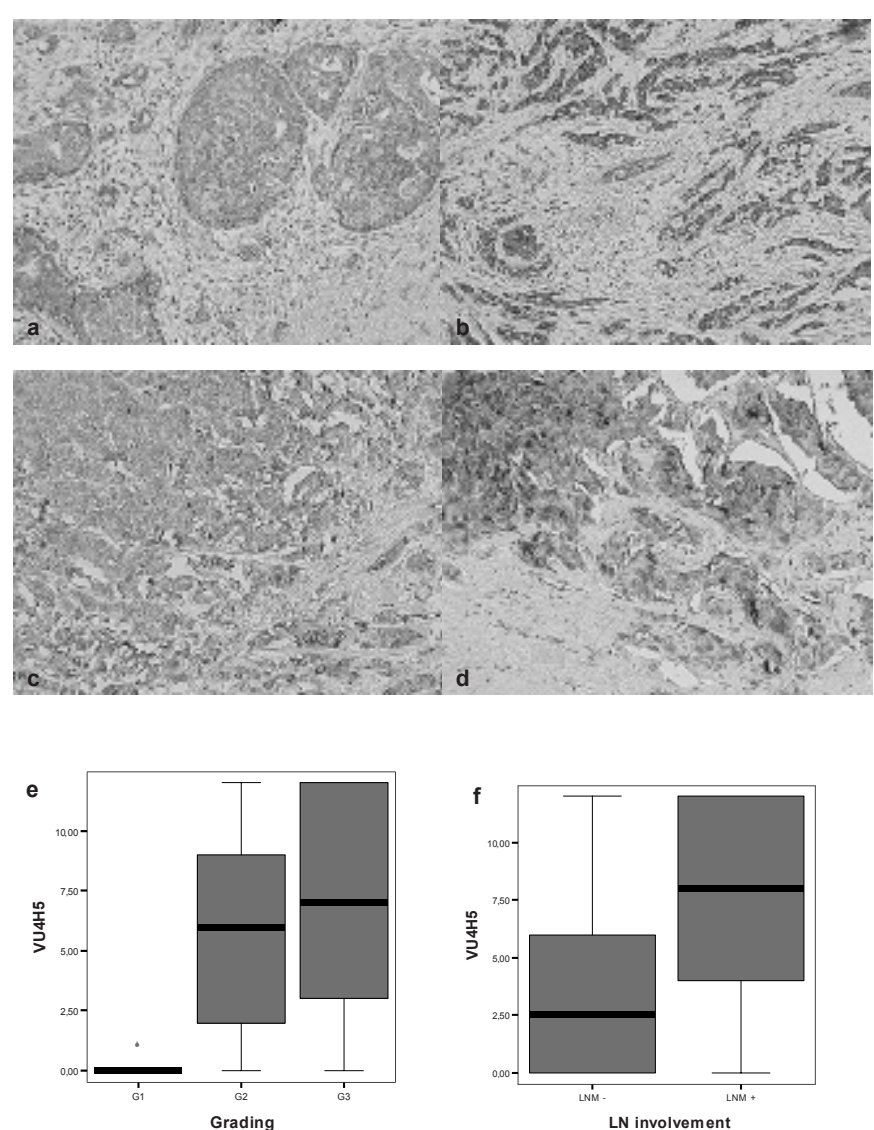

Fig. 4. VU-4-H5 staining in G2 tumors was significantly lower (a) compared to G3 (b) tumors. In ductal carcinomas with lymph node metastasis and expression of ER, increased VU-4-H5 staining from G2 (c) to G3 (d) tumors was observed. VU-4-H5 expression was increased from G1 to G3 carcinomas $(\mathbf{e})(\mathrm{n}=79: \mathrm{G} 1 \mathrm{n}=9, \mathrm{G} 2 \mathrm{n}=38, \mathrm{G} 3 \mathrm{n}=32)$ and from lymph node-negative to lymph node-positive tumors $(\mathbf{f})(\mathrm{n}=79$ : $\mathrm{LN}-42, \mathrm{LN}+$ 37 ). The boxes represent the range between the 25 th and 75 th percentiles with a horizontal line at the median. The bars delineate the 5th and 95th percentiles. The circle indicates values more than 1.5 box lengths. The IRS score is illustrated on the y-axis.

\section{Discussion}

In this study, we investigated a novel anti-MUC1 antibody called PankoMab as a potential new diagnostic tool and compared its ability to define prognostically relevant groups of patients with two established antibodies (DF3 and VU-4-H5) nominally directed against the same antigen. In detail, we examined the relationship between MUC1 expression patterns as seen by the three antibodies in invasive ductal carcinoma of the breast and established tumor characteristics like lymph node involvement, hormone receptor status, and grading. To avoid ambiguous results due to the heterogeneity of breast cancer, we focused on invasive ductal carcinomas, the most common type of breast cancer.

All three anti-MUC1 antibodies were of the same isotype (mouse IgG1). The antibody DF3 was first described in 1984 by Kufe et al. [38]. It was generated with a membrane fraction of breast cancer tissue as immunogen. DF3 is part of the CA15-3 sandwich assay for serum MUC1 [26]. The antibody VU-4-H5 was generated with a synthetic MUC1 peptide consisting of three tandem repeats as immunogen. Both antibodies, DF3 and VU-4-H5, were evaluated during the ISOBM TD-4 International Workshop on Monoclonal Antibodies against MUC1 [27]. As a result of this Workshop, they were confirmed in their MUC1 specificity, and the epitope sequence was determined as APDTRPAP for both antibodies. Nonetheless, the fine specificities were not identical. In immunohistochemistry, DF3 did react with normal gastrointestinal and breast tissues without pretreatment whereas VU4-H5 became positive with normal tissues only after partial deglycosylation by periodate oxidation. In addition, the cellular localization of the antigen analyzed with a MUC1-positive tumor cell line was different [4]. Besides aberrant expression of fully glycosylated MUC1, expression of underglycosylated MUC1 is often found in human carcinomas [28-30]; VU-4-H5 is directed against the core peptide of MUC1 and stains positive only when the MUC1 molecule is underglycosylated, presenting simpler and fewer carbohydrate chains [12,31].

PankoMab [32] is a novel MUC1 antibody explicitly tailored to recognize a tumor-associated MUC1 epitope (TAMUC1) described earlier [33, 34]. This epitope consists of a special carbohydrate-induced conformation of the PDTRP motif. PankoMab has improved tumor selectivity, making it very attractive as a potential therapeutic antibody.

In the present study, we demonstrate that PankoMab may also be suited as a diagnostic antibody. In contrast to the antibodies DF3 and VU-4-H5, PankoMab reactivity revealed a strong correlation with the expression of the ER. No correlation to lymph node involvement was found; however, in our study, the localization of the antigen (membrane versus cytoplasm) was not considered [17]. DF3 showed no correlation with grading, lymph node involvement or ER expression. Only in one subgroup of lymph node-positive, ER-negative tumors, we found significantly reduced DF3 staining in G3 compared to G2 tumors. VU-4-H5 showed increased staining intensity in correlation with increased grading and lymph node involvement, a result in contrast to the data of Luna-More [17], which were obtained with another anti-MUC1 antibody (E29) and considered the cellular distribution of the antigen. 
Because VU-4-H5 detects MUC1 with less glycosylated sugar chains and as glycosylation of mucins is often reduced with tumor progression [35-37], our results on VU-4-H5 staining are in concordance with these findings.

In conclusion, PankoMab is a novel anti-MUC1 antibody with diagnostic potential providing strong correlation with ER expression, a property not shown by the two established antiMUC1 antibodies used for comparison. Its use in combination with VU-4-H5 may be an alternative option in comparison with the established DF3 antibody, which showed no correlation with grading or hormone receptor status.

\section{Supplemental Table File}

Table 1. PankoMab, DF3 and VU-4-H5 staining in ductal breast carcinomas of 82 patients

For further information plase refer to www.karger.com/doi/10.1159/000209280.

\section{Conflict of Interest}

U.K. is an employee of Glycotope, all other authors declare that there are no considerations or conflicts of interest.

\section{References}

1 Jeschke U, Karsten U, Wiest I, Schulze S, Kuhn C, Friese K, Walzel H: Binding of galectin-1 (gal-1) to the Thomsen-Friedenreich (TF) antigen on trophoblast cells and inhibition of proliferation of trophoblast tumor cells in vitro by gal-1 or an anti-TF antibody. Histochem Cell Biol 2006;126:437-444.

2 Zaretsky JZ, Barnea I, Aylon Y, Gorivodsky M Wreschner DH, Keydar I: MUC1 gene overexpressed in breast cancer: structure and transcriptional activity of the MUC1 promoter and role of estrogen receptor alpha (ERalpha) in regulation of the MUC1 gene expression. Mol Cancer 2006;5:57.

3 Gendler SJ, Lancaster CA, Taylor-Papadimitriou J, Duhig T, Peat N, Burchell J, Pemberton L, Lalani EN, Wilson D: Molecular cloning and expression of human tumor-associated polymorphic epithelial mucin. J Biol Chem 1990;265:15286-15293.

4 Cao Y, Karsten U, Hilgers J: Immunohistochemical characterization of a panel of 56 antibodies with normal human small intestine, colon, and breast tissues. Tumour Biol 1998;19(suppl 1):88-99.

5 Croce MV, Isla-Larrain MT, Demichelis SO, Gori JR, Price MR, Segal-Eiras A: Tissue and serum MUC1 mucin detection in breast cancer patients. Breast Cancer Res Treat 2003;81:195-207.

6 Garcia MB, Blankenstein MA, van der Wall E, Nortier JW, Schornagel JH, Thijssen JH: Comparison of breast cancer mucin (BCM) and CA 15-3 in human breast cancer. Breast Cancer Res Treat 1990;17:69-76.

7 Ammon A, Eiffert H, Alhusen R, Weber M, Rumelin B, Groh E, Bartsch H, Marschner N, Nagel GA, Krieger G: Mucin-like carcinoma-associated antigen: sensitivity and specificity in metastatic breast cancer. Onkologie 1990;13:210-214.

8 Hollingsworth MA, Swanson BJ: Mucins in cancer: protection and control of the cell surface. Nat Rev Cancer 2007;4:45-60.

9 Ozzello L, De Rosa CM, Blank EW, Cantell K, Ceriani RL, Habif DV, Sr: The use of natural interferon alpha conjugated to a monoclonal antibody anti mammary epithelial mucin (Mc5) for the treatment of human breast cancer xenografts. Breast Cancer Res Treat 1993;25:265-276.

10 Guddo F, Giatromanolaki A, Koukourakis MI, Reina C, Vignola AM, Chlouverakis G, Hilkens J, Gatter KC, Harris AL, Bonsignore G: MUC1 (episialin) expression in non-small cell lung cancer is independent of EGFR and c-erbB-2 expression and correlates with poor survival in node positive patients. J Clin Pathol 1998;51:667-671.
11 Gaemers IC, Vos HL, Volders HH, van der Valk SW, Hilkens J: A stat-responsive element in the promoter of the episialin/MUC1 gene is involved in its overexpression in carcinoma cells. J Biol Chem 2001;276:6191-6199.

12 Mommers EC, Leonhart AM, von MensdorffPouilly S, Schol DJ, Hilgers J, Meijer CJ, Baak JP, van Diest PJ: Aberrant expression of MUC1 mucin in ductal hyperplasia and ductal carcinoma in situ of the breast. Int J Cancer 1999;84:466-469.

13 Huang L, Chen D, Liu D, Yin L, Kharbanda S, Kufe D: MUC1 oncoprotein blocks glycogen synthase kinase 3beta-mediated phosphorylation and degradation of beta-catenin. Cancer Res 2005;65:10413-10422.

14 Li Y, Bharti A, Chen D, Gong J, Kufe D: Interaction of glycogen synthase kinase 3beta with the DF3/MUC1 carcinoma-associated antigen and beta-catenin. Mol Cell Biol 1998;18:7216-7224.

15 Li Y, Kuwahara H, Ren J, Wen G, Kufe D: The c-Src tyrosine kinase regulates signaling of the human DF3/MUC1 carcinoma-associated antigen with GSK3 beta and beta-catenin. J Biol Chem 2001;276:6061-6064.

16 van de Wiel-van Kemenade, Ligtenberg MJ, de Boer AJ, Buijs F, Vos HL, Melief CJ, Hilkens J, Figdor CG: Episialin (MUC1) inhibits cytotoxic lymphocyte-target cell interaction. J Immunol 1993;151:767-776.

17 Luna-More S, Rius F, Weil B, Jimenez A, Bautista MD, Perez-Mellado A: EMA: a differentiation antigen related to node metastatic capacity of breast carcinomas. Pathol Res Pract 2001;197:419-425.

18 Rahn JJ, Dabbagh L, Pasdar M, Hugh JC: The importance of MUC1 cellular localization in patients with breast carcinoma: an immunohistologic study of 71 patients and review of the literature. Cancer 2001;91:1973-1982.

19 van der Vegt B, de Roos MA, Peterse JL, Patriarca C, Hilkens J, de Bock GH, Wesseling J: The expression pattern of MUC1 (EMA) is related to tumour characteristics and clinical outcome of invasive ductal breast carcinoma. Histopathology 2007:51:322-335.

20 WHO (2003): World Health Organization classification of tumours: pathology and genetics of tumours of the breast and female genital organs; in Tavassoli FA, Devilee P (eds): Tumors of the Breast and Female Genital Organs. Lyon, IARC Press 2007, pp 9-112.
21 Elston CW, Ellis IO: Pathological prognostic factors in breast cancer. I. The value of histological grade in breast cancer: experience from a large study with long-term follow-up. C. W. Elston and I. O. Ellis. Histopathology 1991; 19; 403-410. Histopathology 2002;41:151-153.

22 Non-Operative Diagnosis Subgroup of the National Coordinating Group for Breast Screening Pathology: Guidelines for non-operative diagnostic procedures and reporting in breast cancer screening. NHSBP Publication No. 50. Sheffield, NHSBP, 2001.

23 Jeschke U, Richter DU, Hammer A, Briese V, Friese K, Karsten U: Expression of the Thomsen-Friedenreich antigen and of its putative carrier protein mucin 1 in the human placenta and in trophoblast cells in vitro. Histochem Cell Biol 2002;117:219-226.

24 Jeschke U, Bischof A, Speer R, Briese V, Richter DU, Bergemann C, Mylonas I, Shabani N, Friese $\mathrm{K}$, Karsten U: Development of monoclonal and polyclonal antibodies and an ELISA for the determination of glycodelin in human serum, amniotic fluid and cystic fluid of benign and malignant ovarian tumors. Anticancer Res 2005;25:1581-1589.

25 Mylonas I, Makovitzky J, Jeschke U, Briese V, Friese K, Gerber B: Expression of Her2/neu, steroid receptors (ER and PR), Ki67 and p53 in invasive mammary ductal carcinoma associated with ductal carcinoma in situ (DCIS) versus invasive breast cancer alone. Anticancer Res 2005;25:17191723.

26 Hayes DF, Zurawski VR, Jr, Kufe DW: Comparison of circulating CA15-3 and carcinoembryonic antigen levels in patients with breast cancer. J Clin Oncol 1986;4:1542-1550.

27 Price MR, Rye PD, Petrakou E, Murray A, Brady K, Imai S, Haga S, Kiyozuka Y, Schol D, Meulenbroek MF, Snijdewint FG, von Mensdorff-Pouilly S, Verstraeten RA, Kenemans P, Blockzjil A, Nilsson K, Nilsson O, Reddish M, Suresh MR, Koganty RR, Fortier S, Baronic L, Berg A, Longenecker MB, Hilgers J: Summary report on the ISOBM TD-4 Workshop: Analysis of 56 monoclonal antibodies against the MUC1 mucin. San Diego, CA, November 17-23, 1996. Tumour Biol 1998;19(suppl 1):1-20.

28 Cao Y, Schlag PM, Karsten U: Immunodetection of epithelial mucin (MUC1, MUC3) and mucinassociated glycotopes (TF, Tn, and sialosyl-Tn) in benign and malignant lesions of colonic epithelium: apolar localization corresponds to malignant transformation. Virchows Arch 1997;431:159-166. 
29 Croce MV, Colussi AG, Price MR, Segal-Eiras A: Expression of tumour associated antigens in normal, benign and malignant human mammary epithelial tissue: a comparative immunohistochemical study. Anticancer Res 1997;17:4287-4292.

30 Girling A, Bartkova J, Burchell J, Gendler S, Gillett $\mathrm{C}$, Taylor-Papadimitriou J: A core protein epitope of the polymorphic epithelial mucin detected by the monoclonal antibody SM-3 is selectively exposed in a range of primary carcinomas. Int $\mathrm{J}$ Cancer 1989;43:1072-1076.

31 Cao Y, Blohm D, Ghadimi BM, Stosiek P, Xing PX, Karsten U: Mucins (MUC1 and MUC3) of gastrointestinal and breast epithelia reveal different and heterogeneous tumor-associated aberrations in glycosylation. J Histochem Cytochem 1997;45:1547-1557.

32 Danielczyk A, Stahn R, Faulstich D, Loffler A, Marten A, Karsten U, Goletz S: PankoMab: a potent new generation anti-tumour MUC1 antibody. Cancer Immunol Immunother 2006;55:1337-1347.

33 Karsten U, Serttas N, Paulsen H, Danielczyk A, Goletz S: Binding patterns of DTR-specific antibodies reveal a glycosylation-conditioned tumorspecific epitope of the epithelial mucin (MUC1) Glycobiology 2004;14:681-692.
34 Karsten U, von Mensdorff-Pouilly S, Goletz S: What makes MUC1 a tumor antigen? Tumour Biol 2005;26:217-220.

$35 \mathrm{Li} \mathrm{Y,} \mathrm{Cozzi} \mathrm{PJ:} \mathrm{MUC1} \mathrm{is} \mathrm{a} \mathrm{promising} \mathrm{therapeutic}$ target for prostate cancer therapy. Curr Cancer Drug Targets 2007;7:259-271.

36 Mukherjee P, Ginardi AR, Madsen CS, Sterner CJ, Adriance MC, Tevethia MJ, Gendler SJ: Mice with spontaneous pancreatic cancer naturally develop MUC-1-specific CTLs that eradicate tumors when adoptively transferred. J Immunol 2000;165:34513460.

37 Walsh MD, McGuckin MA, Devine PL, Hohn BG, Wright RG: Expression of MUC2 epithelial mucin in breast carcinoma. J Clin Pathol 1993;46:922-925.

38 Kufe D, Inghirami G, Abe M, Hayes D, JustiWheeler H, Schlom J: Differential reactivity of a novel monoclonal antibody (DF3) with human malignant versus benign breast tumors. Hybridoma 1984;3:223-232. 